addressed to Dr. J. H. Gilbert, and dated "Down, February $16,1876 . "$ The following passage is the one which interests us here :-

"It is admitted by all naturalists that no problem is so perplexing as what causes every cultivated plant to vary, and no experiments as yet tried have thrown any light on the subject. Now for the last ten years $I$ have been experimenting in crossing and selffertilising plants; and one indirect result has surprised me much, namely, that by taking pains to cultivate plants in pots under glass during several successive generations, under nearly similar conditions, and by self-fertilising them in each generation the colour of the flower often changes, and, what is very remarkable, they became in some of the most variable species, such as Mimulus, Carnation, etc., quite constant, like those of a wild species."

We now know that the colour changes and the becoming constant to which Darwin refers were the results of the repeated self-fertilisation of heterozygous material, so that the supposed variability evidently was nothing but segregation after a cross.

Velp, Holland, November 2.

J. P. Lursy.

IT would take too much space to reply in detail to all of Dr. Lotsy's statements, for which I have great respect. They go far outside the original point at issue, but it is necessary to refer to the more important of them, and it will then probably be seen that the others are immaterial. In his original letter (NATURE, October 27, p. 274), which commented on an article of mine on "British Roses and Hybridity" (NATURE, September I5 $_{5}$, p. 99), he states that Jeffrey's work tends "to show that the presence of "bad pollen' is proof [my italics] of a hybrid origin," and goes on to say that this view is "much strengthened" by other work. He correctly states that I took exception to that view, my own view being that "bad pollen" is unsafe as a criterion of hybridity, in support of which I cited various facts. As some of these facts were from a paper of which I was joint author, the original article was unsigned, but since this controversy, which was not of my seeking, has arisen, I prefer to sign my own name. In his present letter Dr. Lotsy seems to forget that the burden of proof rests upon those who assume that bad pollen is a proof of hybridity. He says that my postscript to his article is "not according to facts," and that he did not suggest the hybrid nature of Trillium, Dirca, and Scoliopus. I can only ask, if that is the case, why did he refer to them in his original article? Cytological work, which is by no means all "recent," proves that hybridity is $a$ cause of bad pollen, but by no means proves that it is the only cause.

Dr. Lotsy has apparently omitted a consideration of lethal factors from his views. This is a more recent discovery which is of much significance in the interpretation of sterility, not only in Drosophila, but in various CEnothera forms, and it may apply either to gametes or zygotes. The conception has already been fruitfully applied, not only to various plants and animals, but also to man himself. When I said that the theory of mutation requires the occurrence of a certain proportion of defective germcells I had similar cases in mind, and did not mean to imply that mutations were necessarily always accompanied by germ-cell sterility. But clearly, if lethal factors account for germ-cell sterility in some cases, it is inadmissible to assume that bad pollen is in itself a proof of hybridity. We must apply the conception of multiple causes.

It follows that in any given case, such as that of Oenothera Lamarckiana, bad pollen may have originated from crossing, from lethal factors, or from NO. 2717 , VOL. IO8] some other sause, unless one or more of these possible causes can be eliminated. Dr. Lotsy says, "We now know that $O$. Lamarckiana is a hybrid." One can only ask how we know, and in what sense he is using the term hybrid. So far as the theory of mutation in Enothera is concerned, it no longer matters whether $O$. Lamarckiana is a garden hybrid or not, since the work of Bartlett has proved that various closepollinated wild American species of Enothera show the same mutation behaviour.

Finally, I would say that if by his theory of evolution by hybridisation Dr. Lotsy means merely that the intercrossing of related races is the condition in which evolution has frequently taken place, I, for one, would heartily agree with him. For I have long advocated the view that among open-pollinated plants and most animals the evolutionary unit is an interbreeding population of closely related forms. I fancy many biologists adhere to a similar point of view. But I take it that Dr. Lotsy means much more than that by his theory, and if I understand him correctly, that is his reason for tacitly denying the existence of germinal changes. One can only ask how two visibly similar homozygous organisms when crossed can give rise to new germinal characters if they have not during the previous period of their isolation undergone germinal changes. R. RUGGLES Gates.

King's College, Strand, November II.

\section{Biological Terminology}

(a) "VARIATION is the sole cause of non-inheritance "; $(b)$ "Apart from variations like exactly begets like, when parent and child develop under like conditions "; (c) "The development of the individual is a recapitulation (with additions and subtractions due to variations) of the evolution of the race." Here are three statements which seem to me "in effect " identical. To Dr. Bather the first two seem identical, but not the third. But if the child in his own development step by step recapitulates (with variations) the development of the parent, and the parent in the same way recapitulated that of the grandparent, and so on to the beginning, how, in the world, can the development of the individual be anything other than a recapitulation (with the accumulated variations) of the evolution of the race? If that be so, does not $(b)$ necessarily involve $(c)$ ? $(c)$ is merely $(b)$ applied to a succession of parents and children. Dr. Bather says (NATURE, October 27, p. 27I) that this is not what biologists mean. Then what do they mean? "Recapitulation" must be one of those terrible words which, like "inherit," are used, quite unconsciously, with a number of diverse and even contradictory meanings.

It is pleasant to find that Dr. Bather approves of Prof. Goodrich's address, for probably it has set the heather alight at last. In my humble way I also am enormously pleased. Still, Dr. Bather should bear in mind the history of this matter, some of which Prof. Goodrich indicates. As long ago as the 'eighties Weismann declared that "an organism cannot acquire anything unless it already possesses the predisposition to acquire it." At that time, too, doctors were beginning to insist that not actual diseases, but only predispositions to acquire them, were inheritable. Weismann failed to perceive the necessary consequences of his own idea-predisposition is all that can be inherited in the case of any character; all characters, therefore, are equally and in exactly the same sense innate, acquired, and inheritable. Instead he assumed, with Lamarck, that some characters are innate and others acquired, and so started the famous-or infamous-Lamarckian controversy. Sandeman did, however, very definitely 